ORNL/TM-2014/561

\title{
Application of Super-Hydrophobic Coating to Ballistic Fabric for Enhanced Water Repellency
}

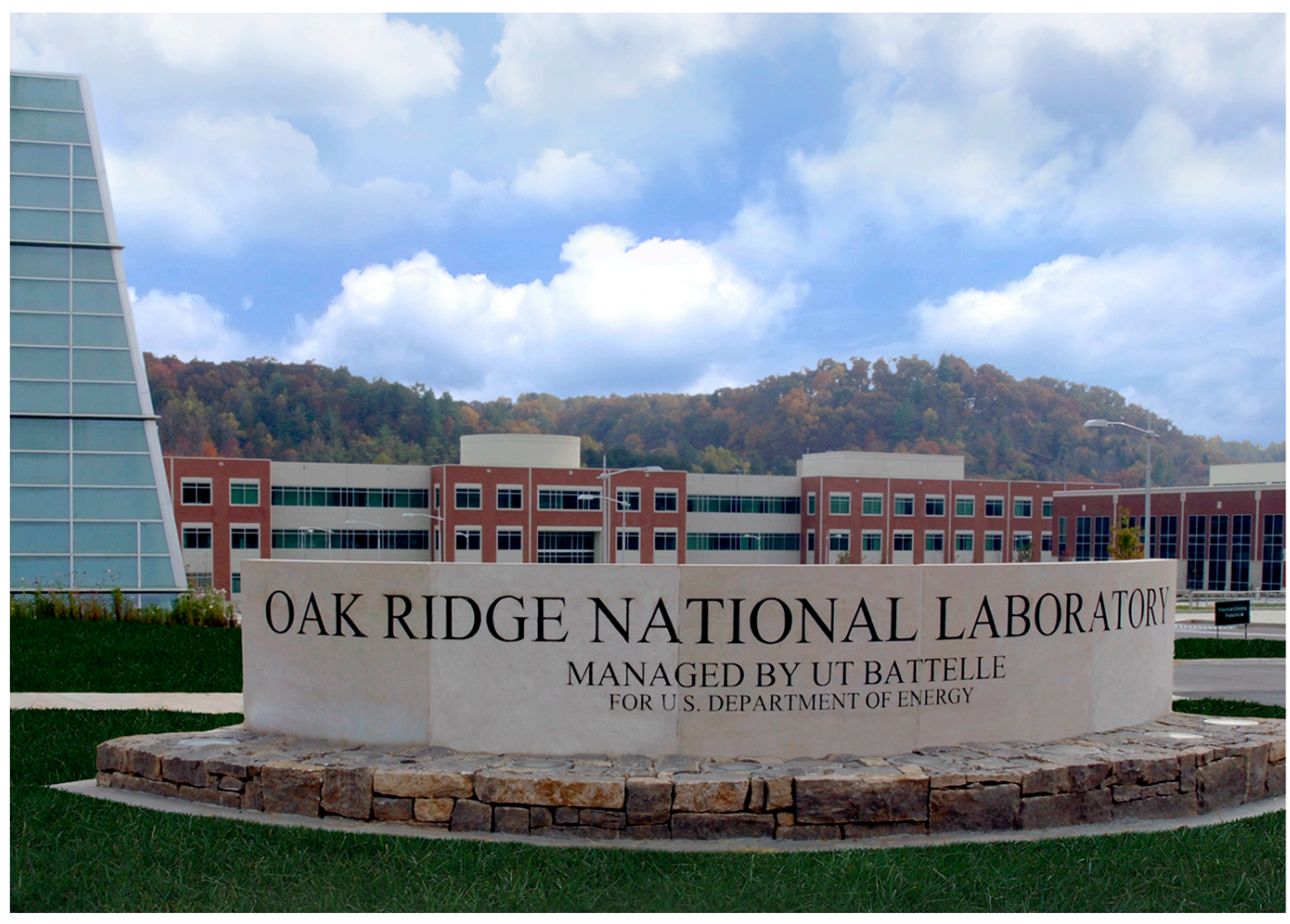

Approved for public release. Distribution is unlimited.
D. Barton Smith

Slobodan Rajic Scott R. Hunter

October 2014 


\section{DOCUMENT AVAILABILITY}

Reports produced after January 1, 1996, are generally available free via US Department of Energy (DOE) SciTech Connect.

Website http://www.osti.gov/scitech/

Reports produced before January 1, 1996, may be purchased by members of the public from the following source:

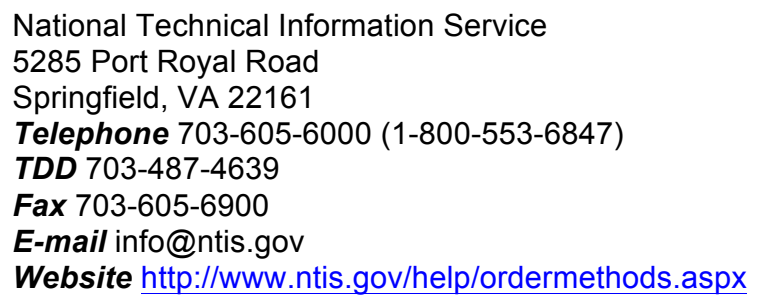

National Technical Information Service

5285 Port Royal Road

Springfield, VA 22161

Telephone 703-605-6000 (1-800-553-6847)

TDD 703-487-4639

Fax 703-605-6900

E-mail info@ntis.gov

Website http://www.ntis.gov/help/ordermethods.aspx

Reports are available to DOE employees, DOE contractors, Energy Technology Data Exchange representatives, and International Nuclear Information System representatives from the following source:

Office of Scientific and Technical Information

PO Box 62

Oak Ridge, TN 37831

Telephone 865-576-8401

Fax 865-576-5728

E-mail reports@osti.gov

Website http://www.osti.gov/contact.html

This report was prepared as an account of work sponsored by an agency of the United States Government. Neither the United States Government nor any agency thereof, nor any of their employees, makes any warranty, express or implied, or assumes any legal liability or responsibility for the accuracy, completeness, or usefulness of any information, apparatus, product, or process disclosed, or represents that its use would not infringe privately owned rights. Reference herein to any specific commercial product, process, or service by trade name, trademark, manufacturer, or otherwise, does not necessarily constitute or imply its endorsement, recommendation, or favoring by the United States Government or any agency thereof. The views and opinions of authors expressed herein do not necessarily state or reflect those of the United States Government or any agency thereof. 


\title{
APPLICATION OF SUPER-HYDROPHOBIC COATING TO BALLISTIC FABRIC FOR ENHANCED WATER REPELLENCY \\ Progress Report \\ June 1, 2013 - May 31, 2014 \\ DOE Proposal No. 2374-V640-12 \\ D. Barton Smith \\ Slobodan Rajic \\ Scott R. Hunter
}

Date published: October 2014

\author{
Prepared for \\ U.S. Army Program Executive Office Soldier \\ Project Manager Soldier Protection and Individual Equipment \\ Technical Management Directorate \\ 10125 Gratiot Road, Fort Belvoir, VA 22060
}

Prepared by

OAK RIDGE NATIONAL LABORATORY

Oak Ridge, Tennessee 37831-6285

managed by

UT-BATTELLE, LLC

for the

U.S. DEPARTMENT OF ENERGY

under contract DE-AC05-00OR22725 


\section{CONTENTS}

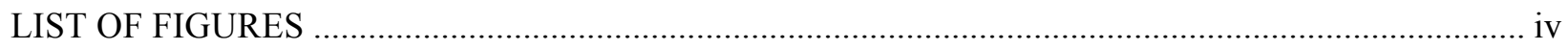

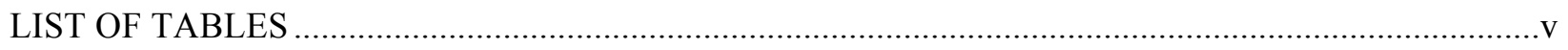

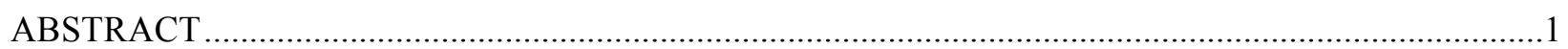

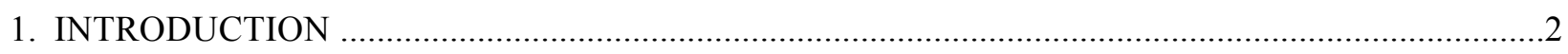

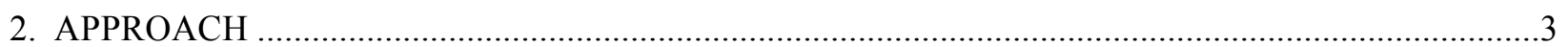

3. RESULTS

3.1 WEIGHT ADDED BY SUPERHYDROPHOBIC COATING …...............................................

3.2 COATING COVERAGE ON YARN AND FIBERS ............................................................

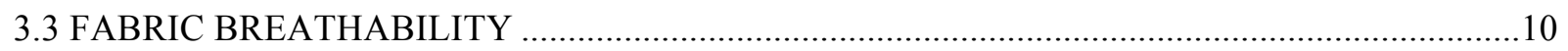

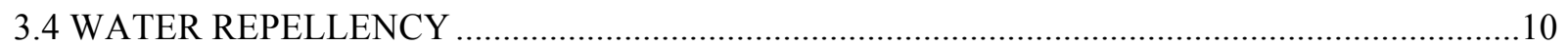

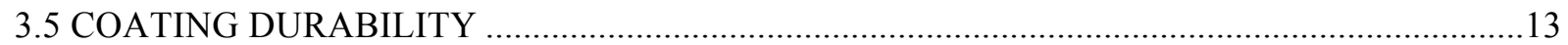

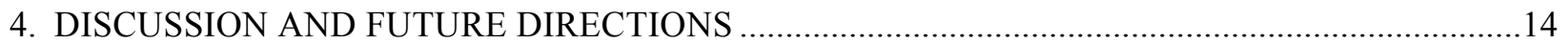




\section{LIST OF FIGURES}

Figure $\quad$ Page

1. Greige and scoured fabric specimens prepared for water repellency studies ...................4

2. Weight measurements (by mass) of greige and scoured fabric specimens before and after treatment with superhydrophobic coating ..................................................

3. Weight increase (by mass) due to superhydrophobic coating ........................................

4. Low-magnification images of uncoated greige fabric ............................................ 8

5. Uncoated and coated fibers in greige and scoured fabrics..........................................

6. Superhydrophobic coatings applied to fibers in greige and scoured yarn ........................9

7. Bubbler apparatus for testing fabric breathability ................................................. 10

8. Uncoated and coated greige fabrics taped to cylindrical mandrel for water droplet

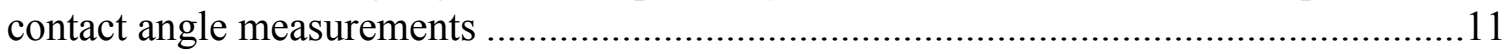

9. Tensiometer images of droplet angle measurements on the undulating surface of the

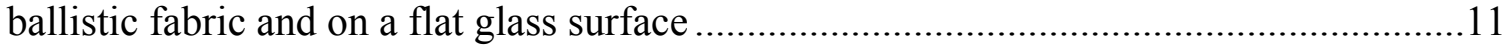

10. Demonstrations of water repellency on untreated and treated fabrics ............................12

11. Simple water column hold-off apparatus for assessing water repellency of fabric

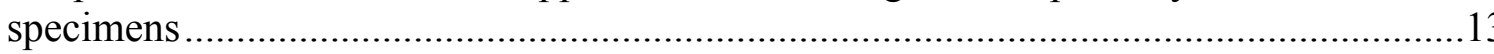




\section{LIST OF TABLES}

Table

Page

1. Mean weight values of specimens before and after coating with superhydrophobic

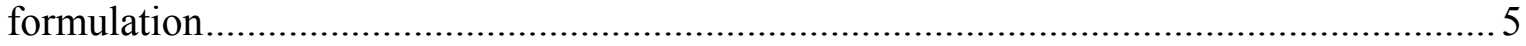

2. Water droplet contact angle (CA) measurements on coated fabrics.............................. 14 


\begin{abstract}
The objective of this work was to demonstrate that a superhydrophobic coating technology developed at Oak Ridge National Laboratory (ORNL) increases the water repellency of ballistic fabric beyond that provided by existing water repellency treatments. This increased water repellency has the potential to provide durable ballistic fabric for body armor without adding significant weight to the armor or significant manufacturing cost. Specimens of greige and scoured ballistic fabric were treated with a superhydrophobic coating and their weights and degree of water repellency were compared to specimens of untreated fabric. Treatment of both greige and scoured ballistic fabrics yielded highly water repellent fabrics. Our measurements of the water droplet contact angles gave values of approximately $150^{\circ}$, near the lower limit of $160^{\circ}$ for superhydrophobic surfaces. The coatings increased the fabric weights by approximately $6 \%$, an amount that is many times less than the estimated weight increase in a conventional treatment of ballistic fabric. The treated fabrics retained a significant amount of water repellency following a basic abrasion test, with water droplet contact angles decreasing by 14 to $23^{\circ}$. Microscopic analysis of the coating applied to woven fabrics indicated that the coating adhered equally well to fibers of greige and scoured yarns. Future evaluation of the superhydrophobic water repellent treatment will involve the manufacture of shoot packs of treated fabric for ballistic testing and provide an analysis of manufacturing scale-up and cost-to-benefit considerations.
\end{abstract}




\section{INTRODUCTION}

The ballistic fabrics used to manufacture body armor for use by soldiers in the US Army must exhibit qualified resistance to various environmental conditions. ${ }^{1}$ One such qualification is established through ballistic testing of a shoot pack system ${ }^{2}$ after the shoot pack is wet conditioned with a liquid such as water. The yarns of para-aramid fiber in the fabric weave experience a temporary loss in tensile strength while they are wet, and they are susceptible to a permanent loss of tensile strength following exposures to saltwater.

Therefore, the para-aramid yarn or fabric is often treated before or after weaving to impart some degree of water repellency to the body armor. These treatments can produce undesirable effects such as the addition of a significant amount of added weight and a permanent loss in tensile strength in the yarns when the yarns are prepared for water repellency treatment via a scouring process that removes the finish from the para-aramid fibers.

An exciting possibility for dramatically increasing the water repellency of a ballistic fabric is the use of a superhydrophobic coating formulated from an admixture of a polymeric binder and nanoparticle silica. In earlier work at Oak Ridge National Laboratory (ORNL) we showed that this superhydrophobic treatment was very effective at imparting outstanding water repellency to fabrics of natural and synthetic fibers used in military clothing. ${ }^{3}$ The treatment formulation is applied using either a dip coating or spray-on technique, and it yields a very durable superhydrophobic surface after it is cured in air or drying oven. The binder has a low volatileorganic-compound (VOC) content and has emission levels below EPA requirements for VOCs used in coatings. In tests performed on the durability of the treated fabrics we observed that the fabrics retained their water repellency for indefinitely long periods. Fabric specimens that were immersed in a water bath for periods of a year or longer were completely dry immediately upon their removal from the bath. This degree of water repellency and durability is unprecedented for post-treatment of textile fabrics. The treatment of the fabrics with the superhydrophobic coating was especially remarkable because there was no reduction in the fabric's intrinsic breathability.

This report describes the results of studies done to determine the degree of water repellency provided by our superhydrophobic treatment on specimens of ballistic fabric, the weight added by the coating and the durability of the treatment. These objectives are aligned with the specifications for technological improvements for body armor issued by the U.S. Army Project Manager Soldier Protective Equipment (PM-SPIE), specifically, improvements in armor processing that allows for overall system weight reduction and improved durability, and improvements to existing high performance fibers that allow for lighter weight armor. ${ }^{4}$

\footnotetext{
${ }^{1}$ DoD Testing Requirements for Body Armor, Report No. D-2009-047, Inspector General U.S. Department of Defense, 29 January 2009; $V_{50}$ Ballistic Test for Armor, Department of Defense Test Method Standard MIL-STD-662F, 18 December 1997.

2 A shoot pack system consists of a ballistic filler packet and a carrier that holds the filler packet. The ballistic filler packet is $15 \times 15$ inches in size and it consists of 28 (or more) plies of water repellent treated fabric. There are additional requirements for the fabric construction and for how the shoot pack system is to be sewn and assembled.

3 John T. Simpson and Scott R. Hunter, "Progress Report: Super-Water-Repellant Fabric Coatings,” May 27, 2012 (unpublished).

${ }^{4}$ See PM Soldier Protective Equipment Broad Agency Announcement for Fiscal Years 2010 through 2015, Section IV, Technical Area 1, Research Opportunity Number W91CRB-10-R-0073-P00001, U.S. Army Project Manager Soldier Protective Equipment, Program Executive Office-Soldier, U.S. Army Contract Command-Aberdeen Proving Ground, issued 10 July 2010.
} 


\section{APPROACH}

For the studies on treatment of fabric with our superhydrophobic coating we prepared specimens from Twaron ${ }^{5}$-fiber fabrics provided to us by Barrday Protective Solutions. Barrday cut twenty cloths each of greige and scoured fabrics into 15 -inch by 15 -inch squares. A greige fabric has been woven from yarn as-received from the supplier and has not been altered or modified after weaving. A scoured fabric has had the finish removed from the fibers either before or after weaving to prepare the surface for treatment with a water repellent or other post-loom treatment. The finishes applied to para-aramid fibers (e.g., Teijin Twaron) after spinning are proprietary in formulation but they are known to be fatty acid glycerides and ester or polyether lubricants. The finish protects the fibers from damage as they are formed into yarns, as they are knitted or woven, and when they are handled in fabrics. We marked the scoured fabric squares with a green marker immediately upon receipt from Barrday to differentiate them from the greige fabric squares. It was impossible to distinguish between the two fabrics by appearance or feel, and care was taken during the studies to keep separate the specimens of the two fabrics.

The superhydrophobic coating was applied in aerosol form using a low-pressure siphon-feed spray gun, and the specimen was sprayed on both sides with a single application of the coating. The specimens were individually sprayed, and the density of the spray (determined by the duration of the spray interval) was adjusted to wet the surface of the fabric until the fabric was just saturated with liquid. Each fiber needs a thin but uniform coating along the entirety of its surface to maximize its water repellency.

To quantify the water repellency of the treated armor we measured the water droplet contact angles and water droplet rolling angles on the treated fabric. The droplet contact angle is a measure of the interaction of the fabric with the surface tension of liquid water. The droplet's rolling angle is a measure of how well the fabric sheds liquid water. Although these two properties are related (i.e., an increase in contact angle typically leads to a decrease in rolling angle), we have found that they are very reliable predictors of the degree of hydrophobicity and water repellency. To qualify as superhydrophobic the droplet contact angle must be at least $160^{\circ}$ and the water rolling angle must be no greater than $5^{\circ}$. Fabric water immersion and penetration tests were also performed to determine the hold-off water pressure for the treated fabric as well as the time required to wet the treated armor.

To quantify the durability of the coating on treated armor we performed a simple abrasion test on coated and uncoated specimens of greige and scoured fabrics. An abrasion test is a semiquantifiable measure of the superhydrophobic coating's resistance to normal wear and to extreme environmental conditions such as wind-blown sand.

\footnotetext{
${ }^{5}$ Twaron is the brandname of a para-aramid fiber manufactured by Teijin Aramid in The Netherlands.
} 


\section{RESULTS}

\subsection{WEIGHT ADDED BY SUPERHYDROPHOBIC COATING}

To obtain statistically significant values for the mass added to the ballistic fabric specimens by a spray application of the superhydrophobic coating, we cut $3 \times 3$ in $^{2}$ squares from the $15 \times 15$ in $^{2}$ squares of untreated greige and scoured Twaron fabrics provided by Barrday Protective Solutions. We cut five specimens from three separate squares of each fabric, and all the specimens were cut precisely to have identical yarn counts in the warp and weft directions.

The specimens of greige and scoured fabrics are shown in Fig. 1. It was necessary to physically alter the individual specimens to distinguish among them for the before and after weightings. Initial attempts to distinguish fabrics with permanent ink were unsuccessful (the ink smeared while spraying the fabrics, making the marks illegible) and we found it necessary to snip corners to denote the specimen number $(i . e .$, no corners $c u t=$ specimen 1 , one corner cut $=$ specimen 2 , etc.). Cutting the corners had the unfortunate consequence of systematically reducing the masses by specimen number, as evidenced by the measurements shown in Fig. 2 where the specimen weight decreased with specimen number with the exception of greige specimen 5 and scoured specimen 1. These outliers were probably the result of an undercount (scoured 1) or overcount (greige 5) of fibers in the yarns at the edges of the squares. Table 1 displays the mean weights of the greige and scoured specimens. The mean weights of the untreated greige and scoured specimens were in agreement within one standard deviation, as expected.

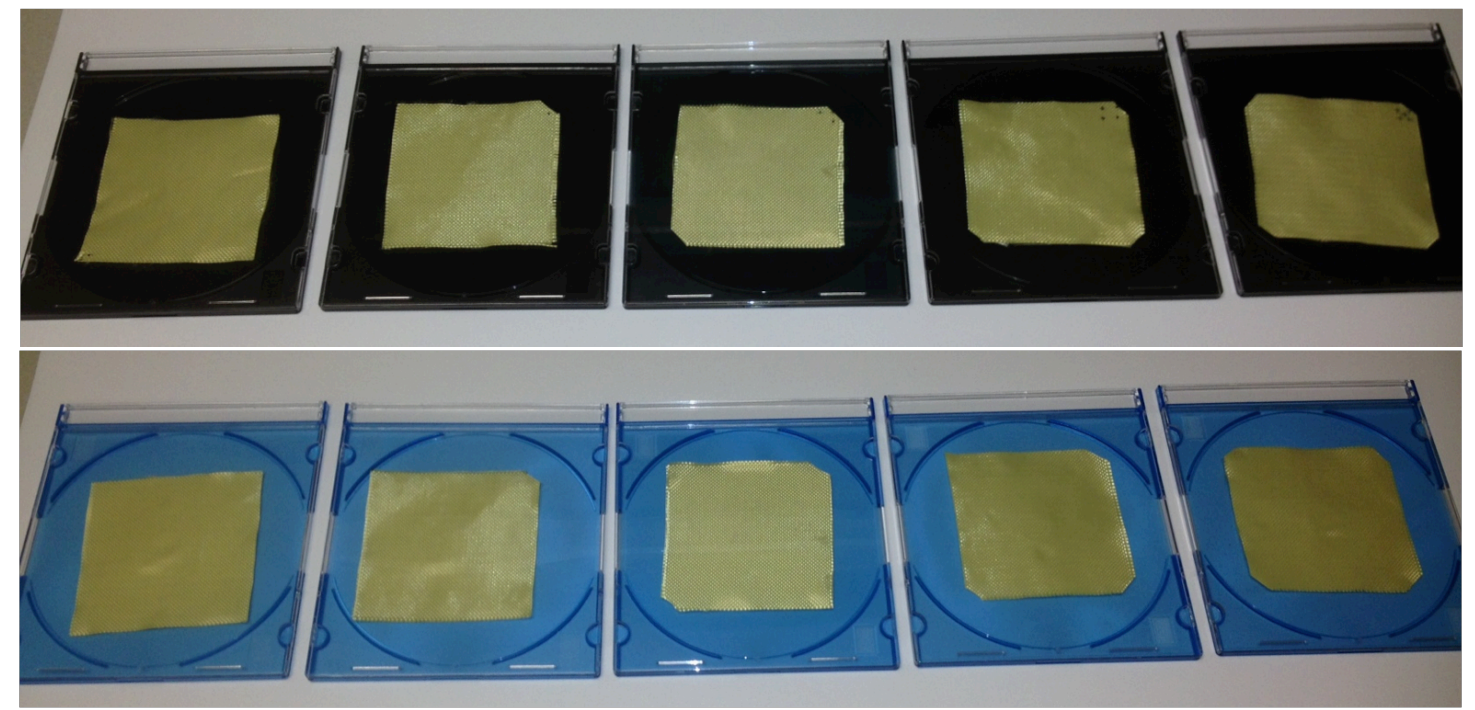

Figure 1. Greige fabric specimens (top photo) and scoured fabric specimens (bottom photo) prepared for water repellency studies. Specimens were denoted by the number of corners cut from the squares.

We endeavored to spray equal volumes of our superhydrophobic coating on each square. If there was variability in the amount of coating applied to individual specimens it could be attributed to overspray and spray bounce-back, which are not reproducible specimen-to-specimen. The measurements of the after-treatment specimen masses are shown along with the pre-treatment masses in Fig. 2. The masses were determined to a precision of 0.0001 grams, and the 
uncertainty in each specimen mass was smaller in magnitude than the size of the symbols used to plot the masses.

Table 1. Mean weight values of specimens before and after coating with superhydrophobic formulation.

\begin{tabular}{cccc}
\hline $\begin{array}{c}\text { Fabric specimen } \\
\left(3 \times 3 \mathrm{in}^{2}\right)\end{array}$ & $\begin{array}{c}\text { Yarn weight, } \\
\text { fabric count }\end{array}$ & $\begin{array}{c}\text { Mean weight }(\mathrm{g}) \text { of } \\
\text { uncoated specimens } \\
{[\mathrm{std} \mathrm{dev}]}\end{array}$ & $\begin{array}{c}\text { Mean weight }(\mathrm{g}) \text { of } \\
\text { coated specimens } \\
{[\text { std dev] }}\end{array}$ \\
\hline Greige & $500 \mathrm{~d}, 28 \times 28$ & $0.7223[0.0131]$ & $0.7670[0.0122]$ \\
\hline Scoured & $500 \mathrm{~d}, 28 \times 28$ & $0.7147[0.0099]$ & $0.7572[0.0079]$ \\
\hline \hline
\end{tabular}

Figure 3 shows the percent increases in the mass of each specimen following application of the coating. The error bars drawn on the data points have a magnitude equal to \pm 1 standard deviation in the mean increase for all specimens. The increases in mass for the greige and scoured fabrics were equal within one standard deviation for four of the five specimens. (Specimens with equal areas, i.e. equal numbers of corners cut, were compared.) Table 1 displays the mean weight values of the greige and scoured specimens after they were coated with the superhydrophobic formulation. The mass of the five greige squares increased by a mean value of $0.0447 \pm 0.0027 \mathrm{~g}$, or $6.2 \pm 0.4 \%$. The mass of the five scoured squares increased by a mean value of $0.0425 \pm 0.0029 \mathrm{~g}$, or $5.9 \pm 0.5 \%$. The increases in weight for the greige and scoured fabrics were in agreement within one standard deviation.

We had on-hand some ballistic fabric from shoot pack samples sent to us by PM-SPIE. This fabric had a water repellent coating applied to it, and although it had a denser weave (i.e., a fabric count of $34 \times 34$ rather than $28 \times 28$, with an unknown yarn weight) it's interesting to compare its weight to that of the superhydrophobic coated fabrics. A $3 \times 3 \mathrm{in}^{2}$ specimen of the shoot pack fabric weighs about $0.119 \mathrm{~g}$. This weight is $40 \%$ greater than that of our superhydrophobic treated fabrics. Even if we allow for a $20 \%$ greater weight due to the denser weave, it appears that the water repellent treatment has added about $17 \%$ weight to the fabric, or about three times more percent weight than the $6 \%$ weight added by the superhydrophobiccoated fabrics. 


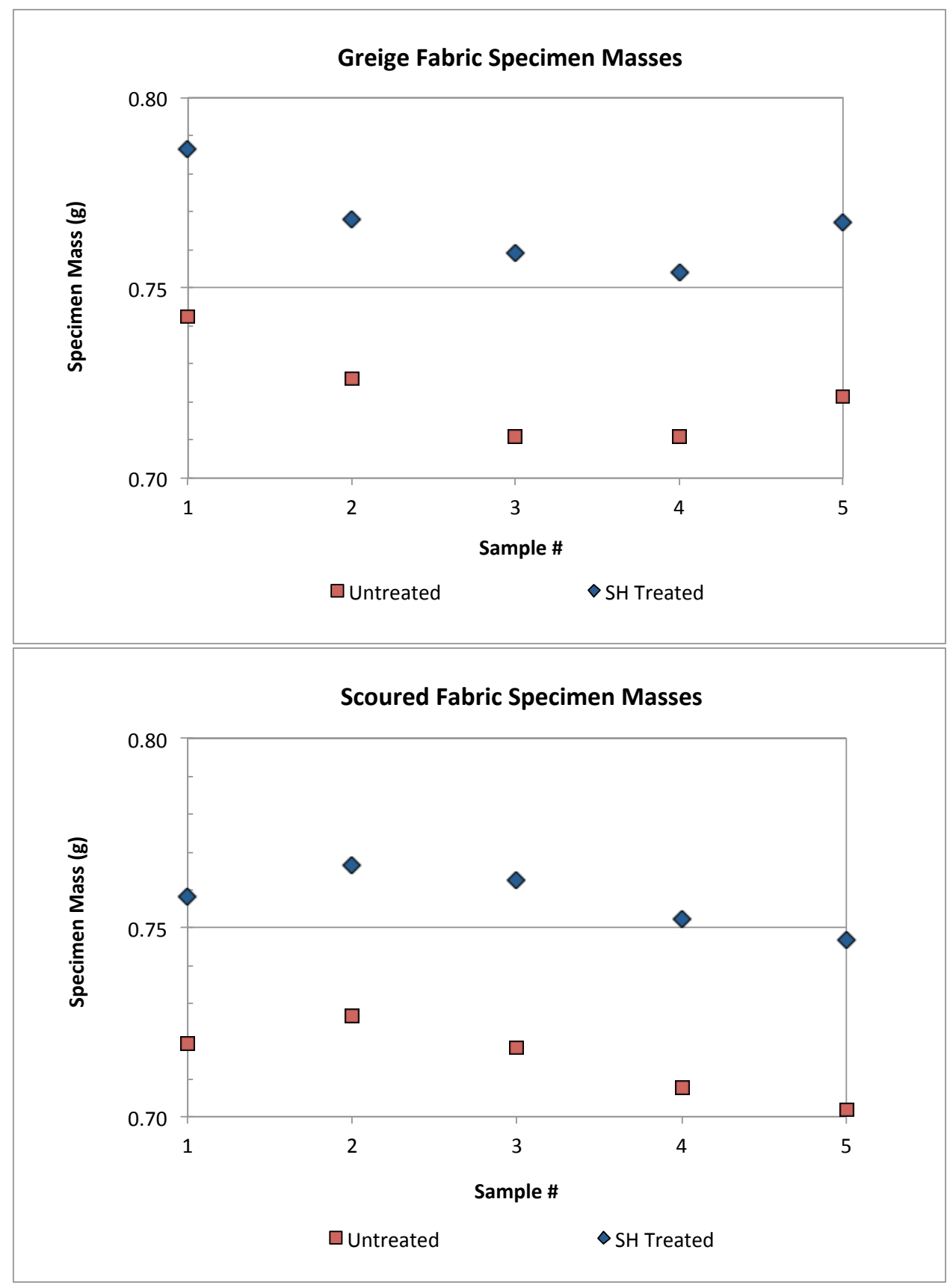

Figure 2. Top, weight measurements (by mass) of five greige fabric specimens before and after treatment with superhydrophobic coating. Bottom, weight measurements of ten scoured fabric specimens before and after treatment. 


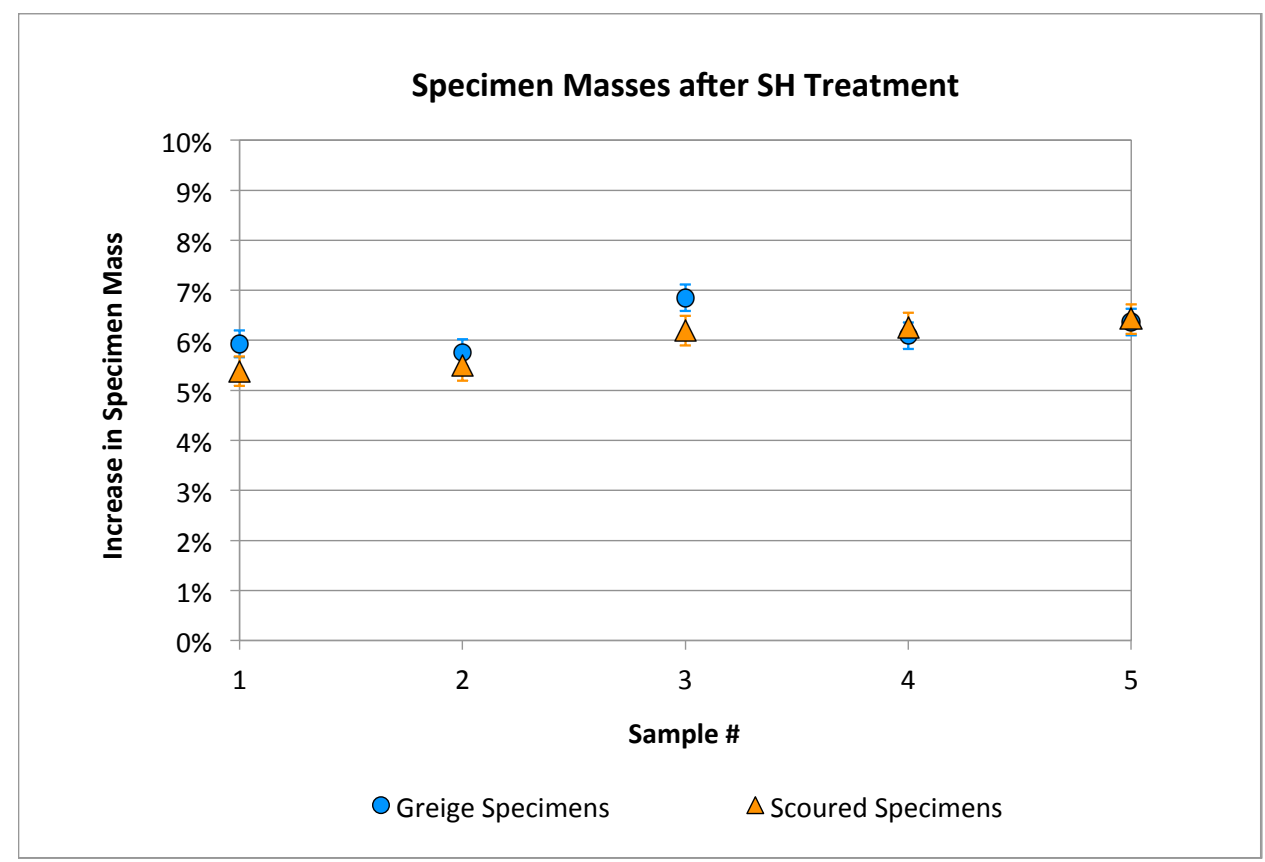

Figure 3. Weight increase (by mass) due to superhydrophobic coating. Error bars are one standard deviation in the mean increase for all five specimens.

\subsection{COATING COVERAGE ON YARN AND FIBERS}

To achieve optimum water repellency of the ballistic fabric, each fiber in the yarn should have a thin, uniform coating of the superhydrophobic formulation along the entirety of its surface. Spraying woven fabrics is not necessarily the ideal method for achieving this coverage, but there are many spray parameters that can be adjusted to improve upon the method and we can usually arrive at very good results through a design-of-experiments optimization.

To assess the coating efficacy of the present spray technique we conducted a microscopic examination of the coatings on greige and scoured fabrics and on yarns pulled from the fabrics. As was the case with the specimens used for the weight increase measurements, the coatings were applied as an aerosol using a low-pressure siphon-type spray gun, and both sides of the fabric were sprayed with a single application of the coating. The density of the spray (duration of the spray interval) was adjusted to wet the surface of the fabric until the fabric was just saturated with liquid.

The yarns were prepared for spraying by mounting them in rectangular fixtures made from conductive foil with a rectangular cutout at the center of the foil. The ends of each yarn were cemented to the foil to stretch the yarn across the cutout. Each yarn was then lightly sprayed on each side with the superhydrophobic coating.

After the treated fabrics were completely dry we cut small $\left(\sim 1 \times 1 \mathrm{~cm}^{2}\right)$ pieces from the fabrics and evaporated a sub-nanometer-thick layer of gold on their surfaces to make the fibers and coating conductive. We also gold-coated similar sized pieces of uncoated greige and scoured fabrics for purposes of comparison. We imaged the uncoated and coated pieces using a scanning electron microscope (SEM) to obtain views of the bare and coated fibers within the weave. 
The images of greige fabric shown in Fig. 4 are representative of the appearance of the fabric weave. The sub-100- $\mu \mathrm{m}$ dust particles present on fabric weave (visible in the SEM image on the right) are electrostatically attracted to the fabric-and though it is possible to move them around on the fabric-it is difficult to remove them completely. As a consequence these dust particles are probably coated by the spray and trapped on the fabric. Their presence under the coating might reduce the durability of the coating.

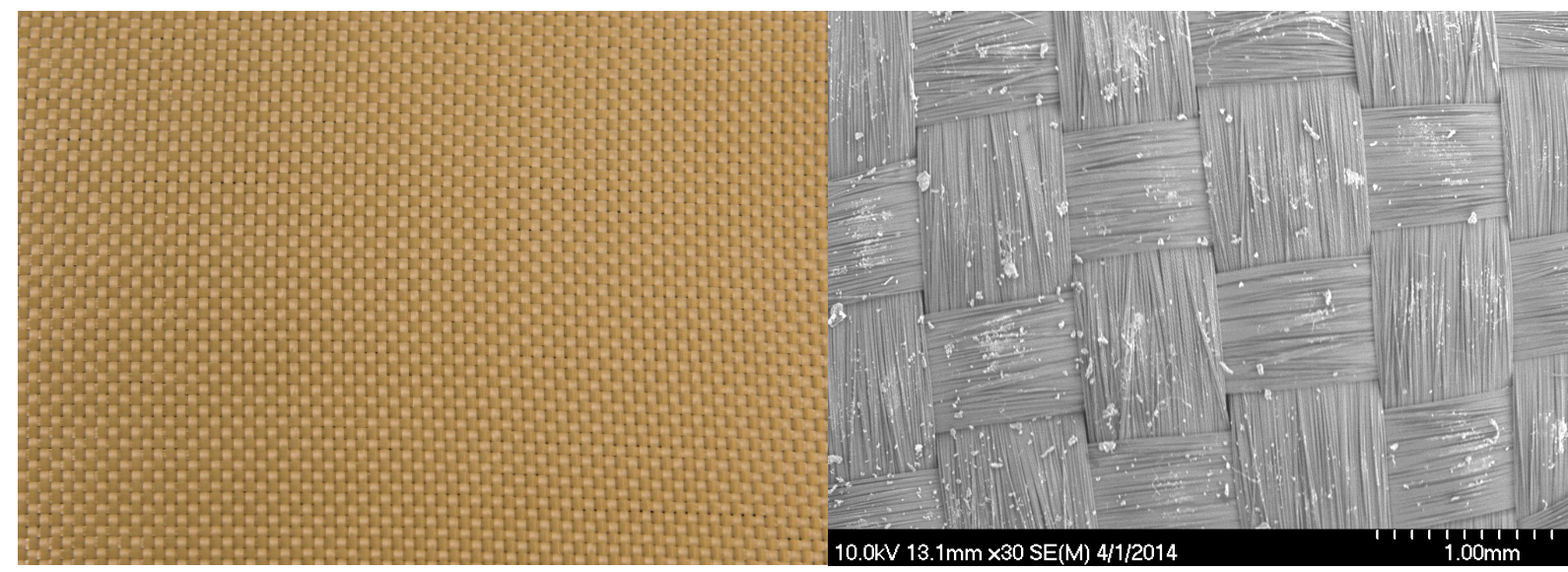

Figure 4. Low-magnification images of uncoated greige fabric. Left, photograph of uncoated greige fabric; right, SEM micrograph of uncoated greige fabric.

Figure 5 shows images taken of yarns within the fabric weave, with and without the superhydrophobic coating. The coating is a matrix of silica particles that are chemically bound to the fibers to produce the superhydrophobic surface. Because the fibers are closely packed together in the yarn, it is difficult to cover the entirety of the fiber surface without adding a coating that is thicker than necessary. In previous work on other fabrics we determined that this too-thick coating didn't harm the fabric. Our observation on the ballistic fabrics is that much of the overcoat tends to come off as a fine powder when the fabric is handled.

Figure 6 displays images of coated fibers in a single yarn. In contrast to the coating applied to yarns in a weave, the coating on a single yarn shows that the coating can be applied much thinner and more uniformly. We noted that there is good adhesion of the coating to fibers in both the greige and scoured yarns. We expect that with a design of experiments study of the spray parameters we can reduce or eliminate the appearance of silica agglomerations in the coating. 

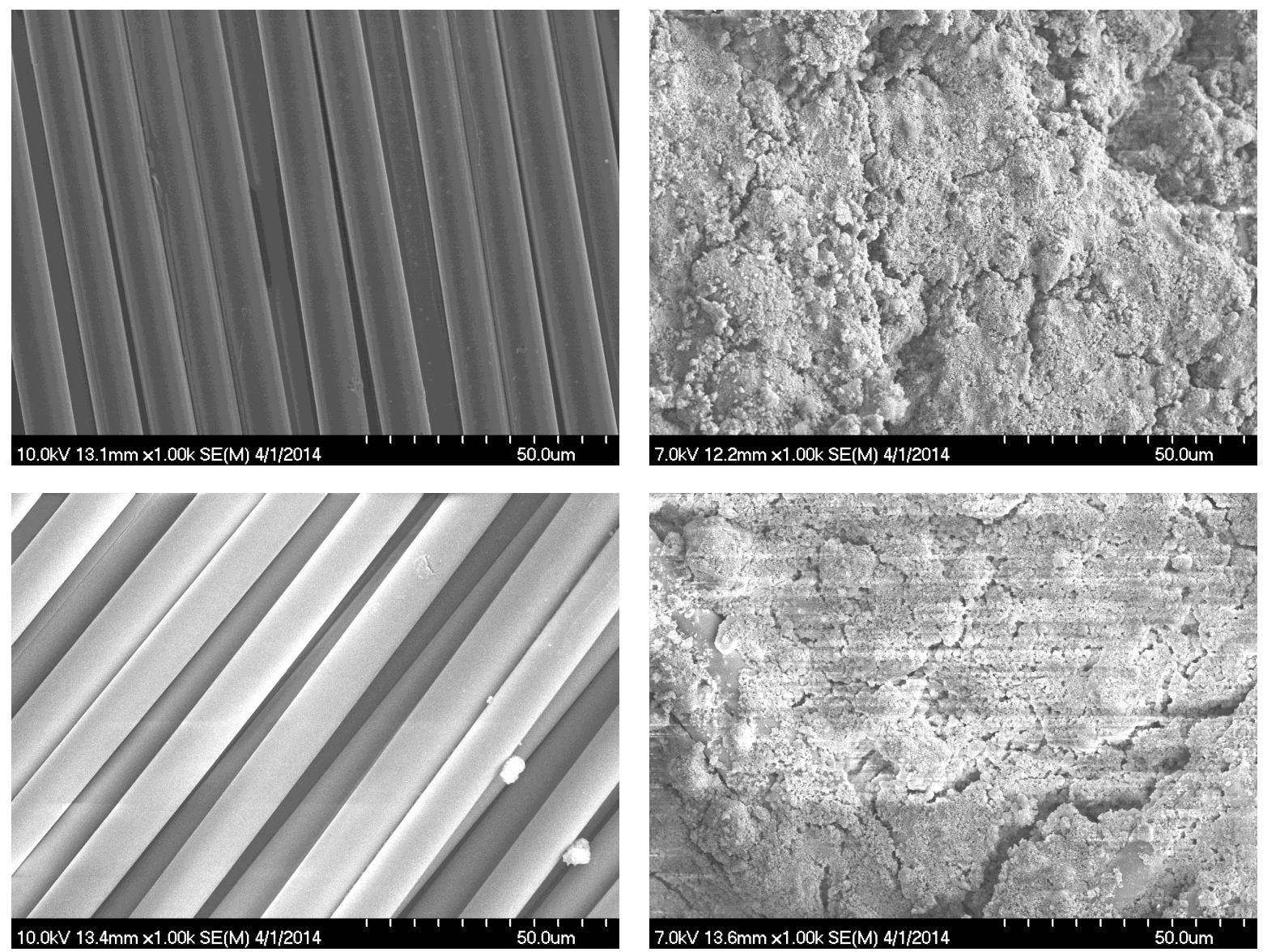

Figure 5. Uncoated and coated fibers in greige and scoured fabrics. Top left, fibers in uncoated greige fabric; top right, superhydrophobic coating on greige fabric; bottom left, fibers in uncoated scoured fabric; bottom right, superhydrophobic coating on scoured fabric. All micrographs taken at $1000 \mathrm{X}$ magnification.
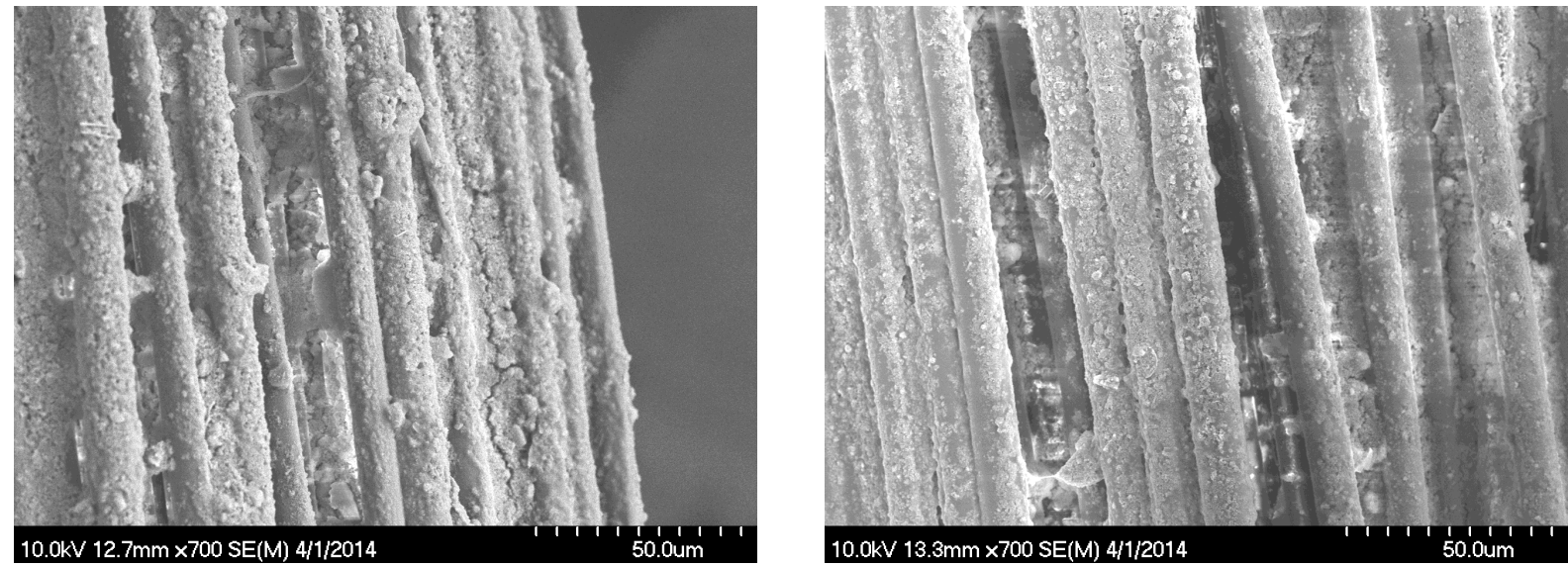

Figure 6. Superhydrophobic coatings applied to fibers in (left) greige yarn and (right) scoured yarn. 


\subsection{FABRIC BREATHABILITY}

We performed a simple evaluation of the air permeability (sometimes referred to as a "breathability test") of the superhydrophobic specimens using a bubbler apparatus. The bubbler consists of a hollow cylindrical base (air chamber) with a clear glass tube of the same diameter extending vertically above the top of the base. A sample of a water repellent fabric is inserted between the base and the tube at their interface. A small volume of water introduced into the clear tube from the top Figure 7. Bubbler apparatus for testing fabric breathability. Presence of large bubbles above the fabric indicates that the fabric pores are open and highly permeable to air.

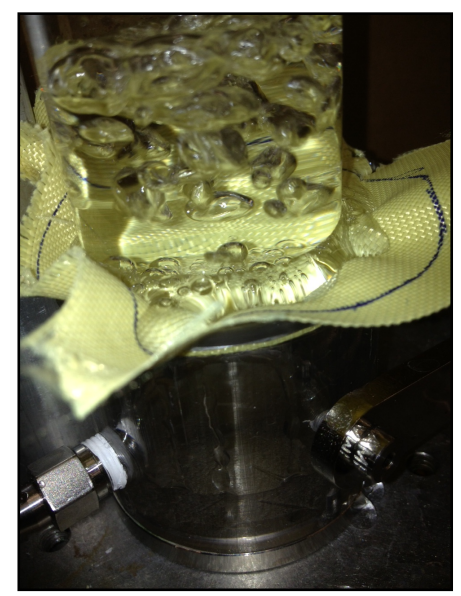
open end will be held in place at the bottom by the water repellent fabric. When the air pressure in the base is increased to a value slightly above atmospheric pressure using a hand bulb, air bubbles should emanate from the top surface of the fabric within a few seconds (see Fig. 7). The breathability of the fabric is ascertained by the time it takes for the bubbles to appear. Bubbles appear immediately when highly breathable fabrics are tested. If more than a few seconds passes before bubbles appear it could be attributable to clogging of the pores in the fabric weave. For samples of coated greige and scoured fabrics we observed the immediate appearance of bubbles at the lowest possible air pressure in the bubbler, which indicates a high degree of breathability in the coated fabrics. For the sake of comparison we tested several specimens of a ballistic fabric from a shoot pack provided to us by PM-SPIE and observed that several seconds elapsed before small bubbles began to appear above the fabric, indicating that the fabric was less breathable than the fabrics treated with our superhydrophobic formulation.

\subsection{WATER REPELLENCY}

To quantify the water repellency of the coated fabrics we performed water-droplet contact angle measurements using a laboratory tensiometer. Tensiometer measurements are usually performed on water droplets resting on surfaces that are flat and smooth so a clear demarcation of the interface between the droplet and the surface can be ascertained by the image analysis algorithm in the tensiometer software. Performing these measurements on textured surfaces such as fabrics can be very challenging. After experimentation with various surface geometries we found that taping the fabric specimens flat on a cylindrical mandrel (Fig. 8) allowed us to obtain the best view of droplet cross sections in our tensiometer's imaging system.

The difficulty in establishing an interface baseline is illustrated by the droplet silhouettes shown in Fig. 9. The image on the left is that of a droplet on the surface of a fabric specimen. The image on the right is that of a droplet on a smooth glass surface. Selecting the baseline slope for the contact angle is much more subjective in the case of the fabric due to the undulations in its surface. 

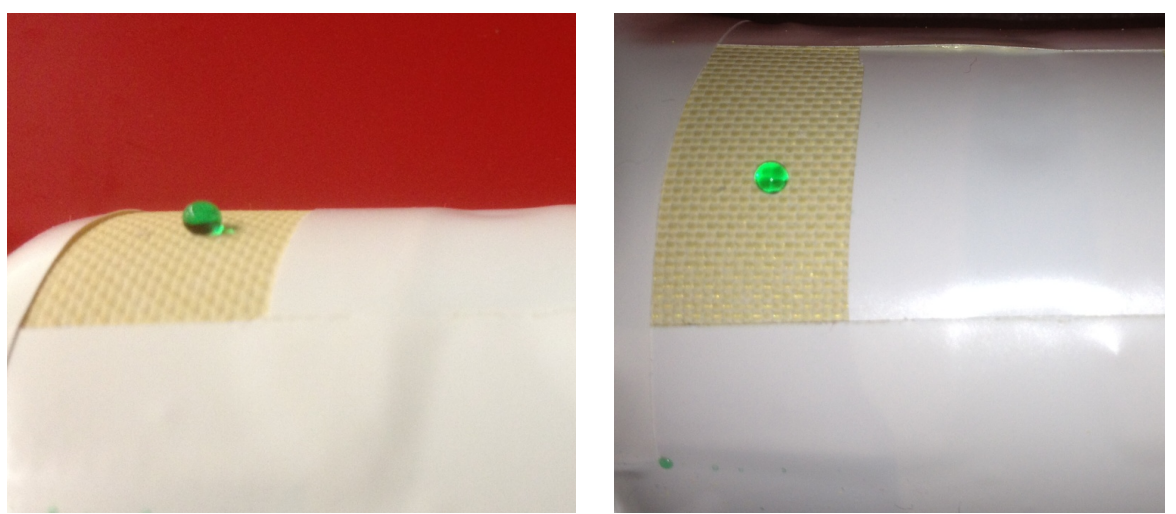

Figure 8. Uncoated greige fabric (left) and superhydrophobic-coated greige fabric (right) are taped to a cylindrical mandrel for water-droplet contact angle measurements. Green dye was added to the water droplets for photographic purposes.
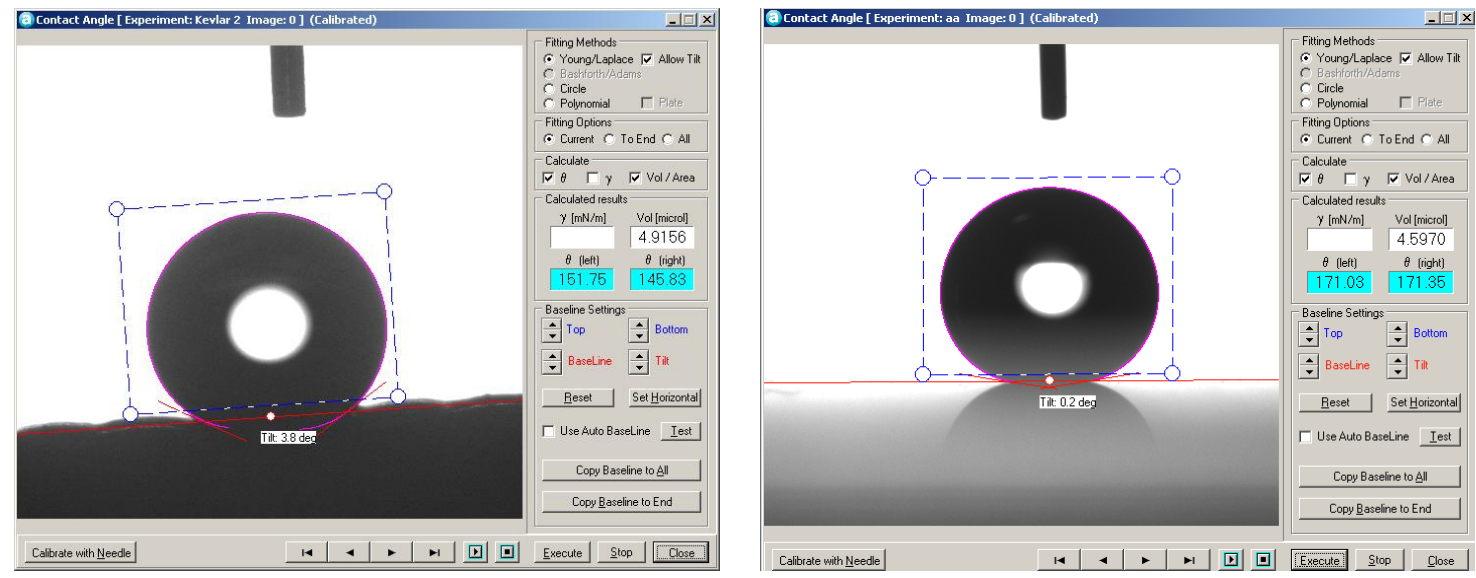

Figure 9. Tensiometer images of droplet angle measurements (left) on the undulating surface of the ballistic fabric and (right) on a flat glass surface.

The contact angle measurements on the coated greige and scoured fabrics showed that the fabrics each had droplet contact angles with values near the $160^{\circ}$ threshold for superhydrophobicity. The greige fabric had a contact angle of $149^{\circ}$ and the scoured fabric had a contact angle of $153^{\circ}$. These contact angles are in agreement within the uncertainty limits for the measurement. The observation that the fabrics are nearly superhydrophobic is further confirmation that they are highly water repellent.

The photographs in Fig. 10 are additional evidence of the excellent water resistance of the superhydrophobic coatings. The photo at the top illustrates the water repellency of a superhydrophobic treated fabric. The uncoated fabric on the left immediately absorbs the water, while the droplets bead up into spheres on the treated fabric on the right. The photo at the bottom shows that the water droplet contact angles on the superhydrophobic coated fabric (right) are significantly higher than those in a specimen of the treated shoot pack fabric (left). 

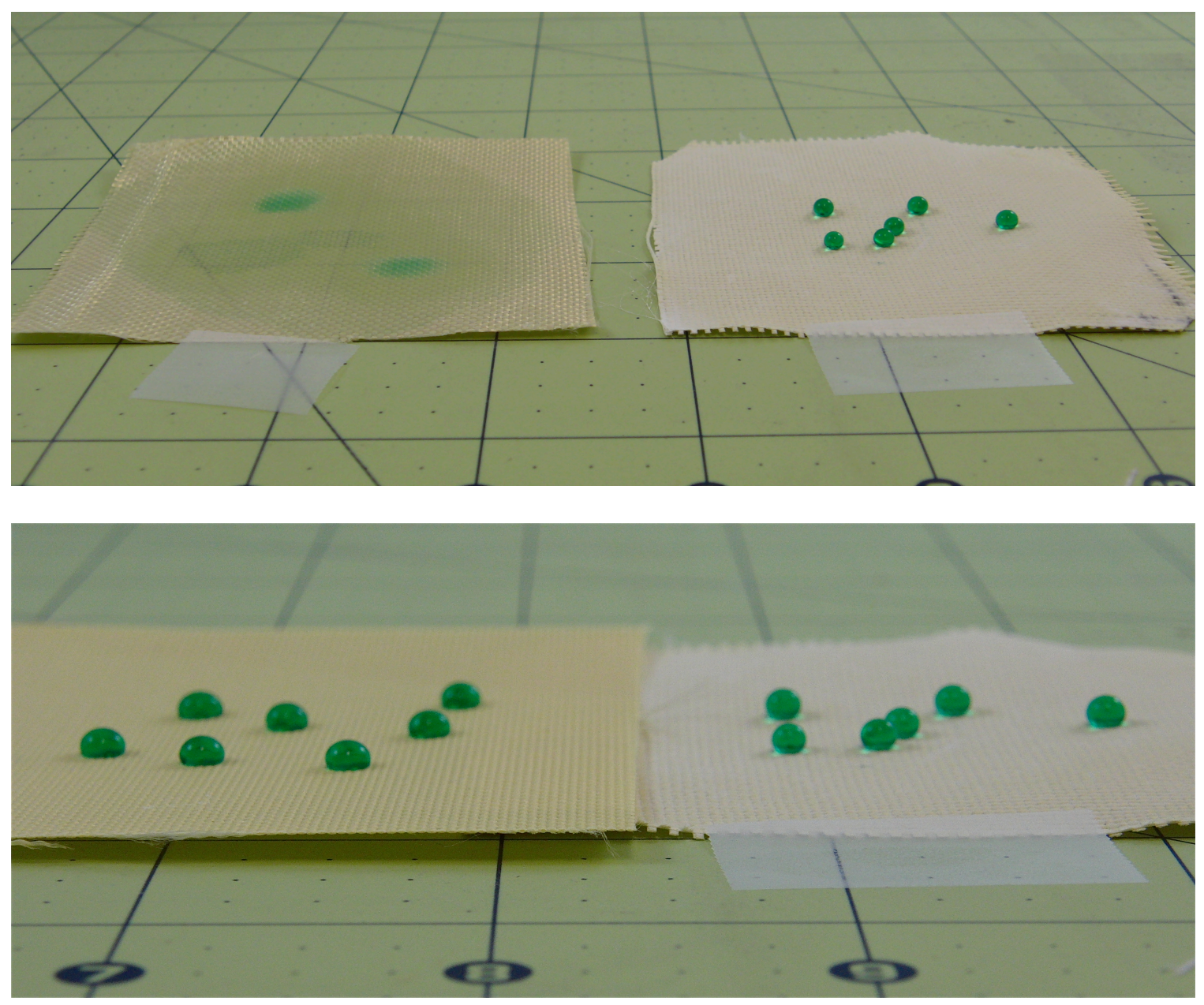

Figure 10. Demonstrations of water repellency on untreated and treated fabrics. Top, water droplets on uncoated greige fabric (left) and ORNL-treated greige fabric (right). Bottom, water droplets on shoot pack fabric (treated with water repellent) (left) and water droplets on ORNLtreated greige fabric (right). The droplets contain a green dye for visualization purposes.

To further assess the water repellency of the superhydrophobic treated fabrics we subjected several specimens of the fabric to a water column test, as illustrated in Fig. 11. We inserted the specimens in the bubbler tester (see section 3.3, above) and began filling the water column while watching the air chamber beneath the fabric for the passage of water through the fabric. It was not possible to precisely reproduce the water column heights in which water began passing through the fabric because the height was strongly affected by the rate at which water was poured into the column. Our general observation was that little or no seepage occurred within a minute for water column heights up to about 14 inches (a differential pressure of about 0.5 PSI). 

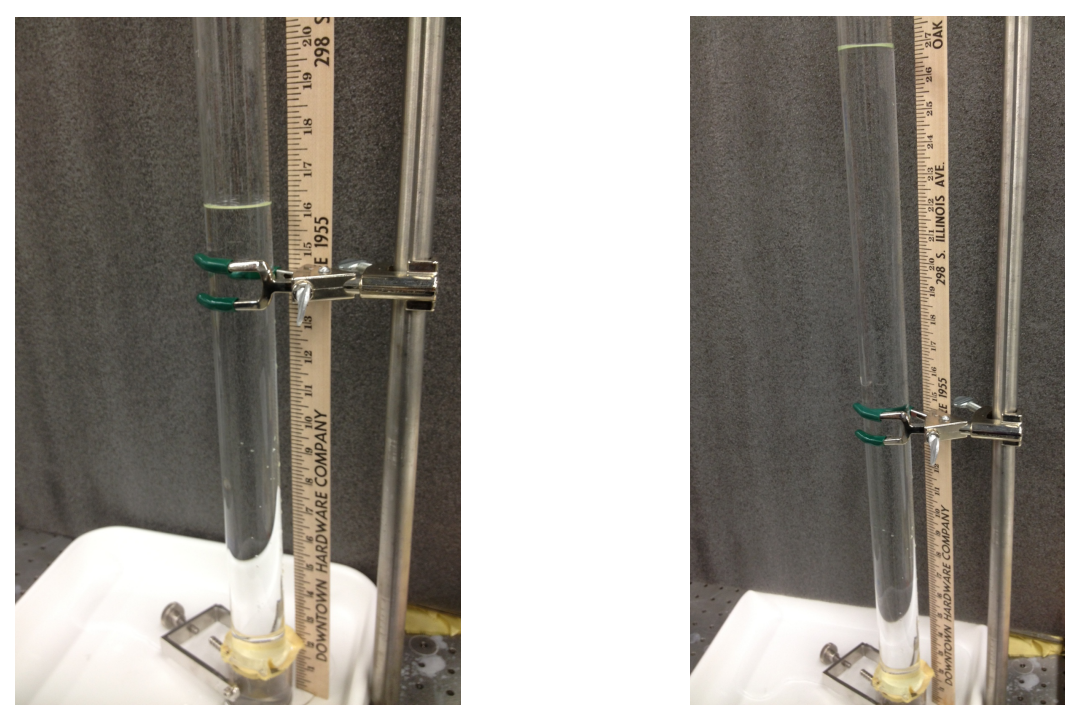

Fig. 11. Simple water column hold-off apparatus for assessing water repellency of fabric specimens.

\subsection{COATING DURABILITY}

We tested the durability of the coatings using a Taber rotary abrader instrument. We subjected the fabric specimens to a single abrasion cycle using CS-0 non-abrasive rubber wheels. CS-5 wheels-made from densely compacted wool felt-are commonly used to abrade textile fabrics and determine the breaking strength of the fibers. However, since we were interested in testing the adhesion of the coating, the CS-0 wheels were deemed more appropriate. The results of the abrasion tests on the fabrics are shown in Table 2. While both fabrics retained a high degree of water repellency, neither fabric remained superhydrophobic in the abraded area. The scoured specimen retained a slightly better water repellency, but a follow-on study with multiple specimens tested would be necessary to establish the significance of this difference.

Table 2. Water droplet contact angle (CA) measurements on coated fabrics

\begin{tabular}{ccc}
\hline \hline Fabric specimen & Initial CA & $\begin{array}{c}\text { CA following } \\
\text { abrasion cycle }\end{array}$ \\
\hline Greige & $149^{\circ}$ & $126^{\circ}$ \\
\hline Scoured & $153^{\circ}$ & $139^{\circ}$ \\
\hline
\end{tabular}




\section{DISCUSSION AND FUTURE DIRECTIONS}

The primary objective of this work was to demonstrate that ORNL superhydrophobic coating technology can provide the required water repellency for ballistic fabric. We demonstrated that our coating is highly water resistant when applied to small-area specimens of fabric, and the application technique is scalable to treatment of long bolts of fabric with implementation of multiple spray heads and a conveyance system for translating the fabric under the spray heads. We plan to move forward with a demonstration of the treatment on a bolt of ballistic fabric that will then be cut into squares for shoot packs and ballistic testing.

The increase in fabric weight due to the addition of the superhydrophobic coating was about $6 \%$ on both greige and scoured fabrics. This weight increase appears to be at least three times smaller than the increase in weight following a conventional treatment. The coating was shown to have good adhesion on fibers in both greige and scoured fabrics even though the spray application is not yet optimized for application on woven fabrics. The polymeric binder used in the superhydrophobic formulation is inert to the fiber chemistry, and there was no evidence in our tests that it is incompatible with the finish on the fibers in the greige fabric. The ballistic tests of treated shoot packs, or tensile tests of treated fibers, will provide confirmation of this observation.

The superhydrophobic coatings that were applied to the fabric specimens were probably thicker than was necessary to achieve excellent water repellency. The thickness of the coating was dictated by the need to have complete coverage of the fiber surface areas. The density of the yarns and the tightness of the weave serves to obstruct the coverage of the fibers during spraying, requiring that the fabric be saturated with formulation to allow penetration to the entirety of the fiber surfaces. Application of the coating to the yarn before weaving or even to the fibers before being formed into yarns would be advantageous for limiting cost and weight. Nevertheless, the process of spraying woven fabric has much opportunity for optimization, either by adjustment of the spray parameters or minor adjustment of the components in the superhydrophobic formulation.

The treatment of the ballistic fabrics with the superhydrophobic formulation yielded a very water repellent fabric, with water droplet contact angles near the superhydrophobic limit and good hold-off to passage of liquid water while maintaining excellent air permeability (breathability) of the fabrics. In addition, the fabric remained more pliable than specimens of similar fabric treated with a conventional water repellent.

Moving forward, the next step in the evaluation of the ORNL superhydrophobic coating treatment is to apply the coating to enough fabric $\left(\sim 160 \mathrm{yd}^{2}\right)$ to prepare the required number of shoot packs for ballistic testing. This treated fabric will then be delivered to an armor manufacturer for cutting and sewing into shoot packs, followed by submission to PM-SPIE for wet conditioning and ballistic testing.

A strategic step is to optimize the binder, solvent and silica powder mixture to yield a formulation that achieves complete coverage of the fibers in the fabric weave without overcoating the fabric with a thicker-than-necessary layer. A valuable parallel investigation would be to explore the possibility of treating the yarns or fibers before the weaving process. 
Finally, we must investigate the requirements for manufacturing scale-up and fully explore the cost-to-benefit of the superhydrophobic coating treatment. To this end we expect to collaborate with armor material supplier on a proposed method for applying superhydrophobic coatings to fabric material during the manufacturing process. Generally speaking, this effort will involve focus on high production rate, low cost production and the issuance of a manufacturing cost analysis based on the proposed manufacturing process. 